\title{
An Ecological Approach to Learning in (Not and) Development
}

\author{
Karen E. Adolph \\ New York University, New York, NY, USA
}

Keywords
Ecological approach · Dynamics of development · Behavioral flexibility

\begin{abstract}
The ecological approach is a framework for studying the behavior of animals in their environments. My version of an ecological approach focuses on learning in the context of development. I argue that the most important thing animals learn is behavioral flexibility. They must acquire the ability to flexibly guide their behavior from moment to moment in the midst of developmental changes in their bodies, brains, skills, and environments. They must select, modify, and create behaviors appropriate to the current situation. In essence, animals must learn how to learn. I describe the central concepts and empirical strategies for studying learning in development and use examples of infants coping with novel tasks to give a flavor of what researchers know and still must discover about the functions and processes of learning (to learn) in (not and) development.

(c) 2019 S. Karger AG, Basel
\end{abstract}

\section{Inspirations for an Ecological Approach}

In my experience, people react to James Gibson's ideas in one of three ways. Some dismiss him as a crackpot, some find his ideas trivial or obvious, and some are instant converts. I was in the third group. I discovered Gibson in a college course on perception. For me, the basic tenets of his ecological approach are profoundly true: behavior of animals in their environments is the phenomenon to be explained; perception, in all its incarnations across the animal kingdom, functions to guide behavior; and perception and behavior, like everything in life, play out in real time (J.J. Gibson, 1958, 1966, 1979).

Eleanor Gibson was a full partner in her husband's ecological approach, but I cannot imagine anyone dismissing her ideas as wacky, trivial, or obvious. Perhaps it

\section{KARGER}

E-Mail karger@karger.com www.karger.com/hde
Karen E. Adolph

Department of Psychology, New York University

4 Washington Place, Room 410

New York, NY 10003 (USA)

E-Mail karen.adolph@ nyu.edu 
was the rigor and clarity of her experiments or her tough, no-nonsense demeanor. Regardless, after her husband's death in 1979, Eleanor Gibson spent another quarter century working on her version of an ecological approach to perception, one that highlighted the roles of learning and development (E.J. Gibson, 1988, 1991, 1997, 2003; E. J. Gibson \& Pick, 2000). I became her doctoral student in this latter part of her career - a rare opportunity to learn from a mentor who spearheaded 70 years of psychological research (Adolph \& Eppler, 2003).

My ecological approach is influenced by both Gibsons, and by my exposure to a dynamic systems framework in Esther Thelen's laboratory, where I conducted the last three years of my doctoral studies with Eleanor Gibson also in residence. It was a special time because Esther was in the midst of formalizing her dynamic systems approach to development (Thelen \& Ulrich, 1991; Thelen \& Smith, 1994), and heated discussions were a daily occurrence. But mostly, my ecological approach is inspired by my detailed observations of infants and young children doing things - goal-directed actions such as navigating obstacles to get to a caregiver, and spontaneous actions such as running around a playroom with no apparent goal in mind. I've described the Gibsons' views elsewhere (Adolph \& Kretch, 2012, 2015; Adolph, Hoch, \& Ossmy, 2020). Here, I focus on my own version of an ecological approach.

\section{Central Ideas}

Several related ideas are critical for understanding my view. Functional behavior of animals in their environments is the phenomenon to be explained. Behavior is functional and adaptive if it allows animals to do the things they need and want to do. Explaining functional behavior is a tremendous undertaking because it is so rich, varied, and complex (Levitis, Lidicker, \& Freund, 2009). Ditto for animals and their environments.

Behavior entails motor action (Adolph \& Berger, 2006; Adolph \& Robinson, 2015; Adolph \& Hoch, 2019). So much so that the terms are largely interchangeable. When body parts move - to walk, talk, eat, reach, look, laugh, keep balance, turn a dial, hammer a peg - those actions are behaviors. When body parts repress, squelch, or dampen movements (e.g., freezing, keeping a straight face, standing at attention), those actions are also behaviors. Behaviors can be spontaneous movements, elicited responses to stimuli, or planned actions intentionally directed toward achieving a goal. All types of behavior can be important for function, learning, and development.

Animals and their environments share a reciprocal relationship; together they form a behavioral ecosystem (Adolph \& Berger, 2006). The animal in the system is a specific example of some type of animal at a specific point in its life history (e.g., a particular 12-month-old human infant with a particular body and brain, and particular skills and experiences). Reciprocally, an environment is the accessible surroundings for a particular animal in a particular place and time (in James Gibson's 1979 terms, the animal's "ambient environment"). The environment includes surfaces, places, objects, other active agents, and the medium that encompasses it all (air for humans and birds, water for fish, etc.). Global generalizations about humans, infants, or 12-month-olds, or about species-typical environments, or children's home environment can be useful abstractions, but only the particulars comprise an actual animal-environment ecosystem. 
Why must the notions of animal and environment entail such specificity? The specificity is necessary because possibilities for action depend on the particulars of the animal's body and skills relative to the features of the accessible environment (Franchak \& Adolph, 2014). Behaviors are possible only if the animal's capabilities and the features of the environment are aligned. This fit between animal and environment that makes a specific behavior possible is what James Gibson (1979) called an affordance. (If his invented term "affordance" is off-putting, mentally replace it with "possibilities for action.")

Development and learning are big, messy concepts. So, I restrict their scope to make them more tractable for study. For the purpose of understanding the animalenvironment ecosystem, development describes important changes in the system, and learning is what the animal does about it. Instead of juggling learning and development, I consider learning in development, and I focus on the type of learning that makes behavior functional.

Development includes changes in the animal's body (size and strength of limbs, etc.), brain (and nervous system), and skills (acquisition of new abilities such as reaching and walking and improvements in abilities such as straighter, faster reaches and steps). Thus, development involves the emergence of new capacities and abilities and opens up new opportunities for acting in the world (E.J. Gibson, 1988). As Witherington (2019) put it, the animal's "powers" - what it can do, given the appropriate environment - are potentials for behavior that exist across extended periods of time and across different environments and situations. The animal's behavior - what it actually does - exists only in the present moment. From conception to death, animals are always behaving and developing. Behavior can influence development by inducing, facilitating, or maintaining changes in powers, and the available powers in turn constrain and promote behavior (Gottlieb, 1991).

Moreover, the environment also develops. Developmental changes in an animal's body, brain, and skills can reshape the accessible environment (surfaces, objects, and agents that can be perceived or interacted with). The ability to sit up, for example, brings more of the world into view. The acquisition of independent mobility brings new parts of the world into play (Campos et al., 2000). Debilities due to chronic illness or aging can shrink the accessible environment. In addition, the environment can develop due to outside influences: think of the uterine and extrauterine environments. Because development changes the relations between the animal and its environment, development alters the landscape of possible behaviors; it changes the affordances for action (E.J. Gibson, 1988; Adolph \& Robinson, 2013, 2015).

Learning is what an animal must do to cope with or exploit changing affordance relations. The most important thing that animals learn about affordances is behavioral flexibility - the ability to tailor ongoing behaviors to changes in local conditions, to select and modify behaviors based on changes in the body, skills, environment, or task (Bernstein, 1996; Adolph \& Berger, 2006; Adolph, 2008; Adolph \& Robinson, 2013, 2015; Adolph \& Hoch, 2019; Rachwani, Hoch, \& Adolph, in press). Flexibility also includes transfer of means from one situation to another (using known actions to solve new motor problems) and the generative and creative aspects of behavior (creating new actions on the fly). Actions are possible or not, regardless of whether affordances are perceived. But perceiving affordances is what animals must do for behavior to be adaptive and functional. Thus, flexibility entails perceiving and exploiting affordances, and using tools or rearrangements of the environment to create 
new affordances for action. Flexibility is essential because novelty and variability in local conditions are the rule, not the exception.

Hence, learning and development are not juxtaposed or parallel processes, and learning is not a sped-up version of development. Rather, acquisition of flexibility is a process that occurs in the context of development (Adolph \& Robinson, 2015; Adolph, Hoch, \& Cole, 2018). Development brings about new affordances for action and new opportunities to learn about the affordances. However, development is not impervious to experience. Behavioral experiences certainly influence developmental changes in the animal-environment system (lifting weights makes muscles stronger; practice improves skill performance; experience affects neurophysiology, etc.). And learning about affordances can influence development through behavioral experiences (e.g., infant learns furniture affords pulling to stand, then practices standing and thereby increases balance control and leg strength). But generally, learning about affordances is nested in and responsive to developmental changes in the animal-environment system, and learning can take any amount of time, from milliseconds to years.

Real time is the time in which the behavioral event occurs. So, actions must be controlled in real time by information obtained before and during the movement. Obtaining information also happens in real time when it is accomplished by perception. Perceiving and acting are a continuous loop, where feedback from just prior movements provides information about what to do next. Typically, animals learn about the current relations between self and environment through exploratory behaviors that generate information for perception (E.J. Gibson, 1988; Adolph \& Berger, 2006; Adolph \& Robinson, 2015). The animal can then use the perceptual information to guide behavior. Thus, exploration involves information-generating behaviors, and action involves using the information obtained. Exploratory movements can be deliberate and intentional, but they needn't be. Spontaneous movements can work just as well for generating the requisite information to guide behavior. Social information from others can also be used to guide behavior. Animals can request social information, or it can be offered unsolicited.

The study of development and learning must take inter- and intraindividual variability into account (Adolph \& Robinson, 2013, 2015; Adolph, Cole, \& Vereijken, 2015; Adolph et al., 2018; Rachwani et al., in press). Developmental events, timing, and pathways differ widely among individuals, so interindividual variability in affordances is pervasive, and thus behavior must be studied at the level of the individual. Intraindividual variability is also rampant in behavior because movements cannot be performed in exactly the same way on repeated occasions. Variable performance can indicate inconsistency in motor control, especially in early periods of skill acquisition, but it can also be a natural outcome of dynamic stability, or it can reflect a variety of means to achieve a desired outcome (Bernstein, 1996). Regardless, intraindividual variability can provide the raw material for selection, refinement, and innovation of behavior.

\section{Scope of an Ecological Approach}

My ecological approach is a framework for studying learning in development how animals acquire the flexibility to guide their actions in real time in a system that is continually in flux. The overall goal is to understand the functional behavior of 
animals in their environments. The empirical strategy is two-pronged. (1) Characterize the developing ecosystem. Identify changes in an animal's body, skills, and environment so as to understand changing opportunities for learning and doing. This can be accomplished by charting the trajectory of a developmental change or by comparing various developmental time points. (2) Examine learning and doing in the context of development. Determine whether the animal's behaviors are sensitive to and capitalize on affordances for action.

Answering such questions involves a lot of descriptive work, accomplished through both naturalistic studies and controlled laboratory experiments. As Esther Thelen (1996) wrote, "To understand behavior, you have to know what it looks like. You need to see what form the behavior takes, how frequently and under what circumstances it is performed, and how it changes" (p. 24). Indeed, a theme at a meeting of a recent international conference was the virtue of hypothesis testing versus discovery science. I was a keynote speaker and did my usual song and dance about learning in development, behavioral flexibility, and perceiving affordances. During a question and answer period, one of the discussion leaders asked the audience to raise their hands if they liked my presentation. In mute embarrassment, I turned my head and thankfully saw a sea of hands. Then he asked them to keep their hands up if they thought my work was hypothesis-driven, and nearly all the hands came down. Although I sometimes test specific hypotheses about behavior, I would in fact classify most of my work as descriptive. In my experience, rich description leads to even richer - often surprising - answers and discovering new phenomena can be more exciting and satisfying than confirming hypotheses.

Unfortunately, the widespread practice in developmental psychology is to sidestep the foundational descriptive questions and to jump straight to testing hypotheses about presumed mental abilities or neural underpinnings. Thus, researchers know relatively little about the acquisition of functional behavior in infants and children. I worry that much of the work in developmental psychology - including my own - is far removed from the real-life phenomena we wish to explain (Adolph, 2020). The good news is that there is still plenty to do.

My ecological approach is not offered as a grand theory, but the scope is broad enough to answer critically important questions about behavior. Following the Gibsons (E.J., 1982, 1991; J.J., 1979), my framework is not a human-centered approach (Adolph \& Robinson, 2015), and I do not aspire to identify psychological functions that are uniquely human. My aim is something bigger. I specialize in human animals in their human environments, but that is only incidental; many animals are equally fascinating, and my central ideas should hold for all animals that use perception to guide behavior in a changing ecosystem. I concentrate on the infancy period because the changes are dramatic, rapid, and meaningful (to infants, caregivers, clinicians, funders, and policy makers). Although varied child-rearing practices and geographical environments affect infant motor development (Adolph, Karasik, \& TamisLeMonda, 2010; Adolph \& Robinson, 2013, 2015), I primarily study infants in the vicinity of my lab; nonetheless, my ecological approach is applicable across cultural and geographic contexts. And although I recognize that functional behaviors include social interactions and communication, I focus on postural, locomotor, and manual actions because the affordances are relatively straightforward. Following in the footsteps of the great pioneers in motor development (Gesell, 1933; McGraw, 1935; Thel- 
en \& Ulrich, 1991), I use the phenomena and processes of infant motor behavior as a model system to understand issues of general interest to behavioral scientists and developmental psychologists (Adolph \& Berger, 2006; Adolph \& Robinson, 2013, 2015; Adolph et al., 2018; Adolph \& Hoch, 2019).

\section{A Functional Approach}

Developmental researchers have a choice: study complex behavioral phenomena with all the inherent noise and complexity or simplify the behaviors to make the phenomena easier to study (Adolph et al., 2018; Lee, Cole, Golenia, \& Adolph, 2018). Following the Gibsons (1982), I aim to resolve the tension between ecological validity and experimental control by adopting a functional approach to behavior. A focus on the functions of behavior helps to ensure that laboratory experiments and naturalistic studies contain the essential elements of behavioral phenomena that serve a purpose in infants' everyday lives. Put another way, not all behaviors are equally profitable to study. To explain the functional behaviors of animals in their environments, it is useful to study animals behaving in their environments or to ensure that laboratory tasks capture the critical elements (J.J. Gibson, 1979; Adolph, 2020). Failing that, the whole enterprise is likely to fail.

\section{The Animal-Environment Ecosystem}

With a focus on functional behavior, the system to be studied is the animal-environment ecosystem. The trick is to select the appropriate grain size for analysis, not so large that important details about the child's behavior are lost, and not so small that critical factors about the child and environment are eliminated. In an overly broad macrosystem that includes children's cultural, political, and geographical environment, the behaviors of individuals are swamped. In an overly simplified microsystem (e.g., infant's legs stepping on a motorized treadmill; infant's eyes watching a computerized display), only parts of the child's behavior are accessible for study, and the whole child and accessible environment are lost.

The just-right grain size includes all the proximal influences on behavior - the current status of the child's body, brain, and skills, the features of the accessible environment, and the immediate social and cultural influences that create, constrain, and facilitate behavior. In short, the ecosystem includes the embodied, embedded, and enculturated aspects of behavior (Adolph \& Robinson, 2015; Adolph et al., 2018; Adolph \& Hoch, 2019). Thus, a useful system for study is a child freely behaving in a complex physical and social environment. This grain size is tractable, and many research paradigms are possible. Naturalistic studies in the "wild" yield data on everyday behaviors. Studies in the laboratory allow greater precision in the procedures to elicit behavior and in the technologies to record it.

In any context, if children are allowed to behave freely, they will spontaneously emit a universe of behaviors to explore and exploit affordances. Many affordances seem straightforward: grasp this, sit here, walk there. But other affordances are less apparent to a newcomer. The affordances of most everyday artifacts involve highly specific, often arbitrary, designer-determined actions - twist left, not right, to open a 
jar lid; pull down initially, not up, to open a window shade (Gaver, 1991; Rachwani, Tamis-LeMonda, Lockman, Karasik, \& Adolph, 2019). And many designed actions are not readily specified by visual or haptic information (Bix, de la Fuente, Sunder, \& Lockhart, 2009; Norman, 2013). Through exploration, observation, and instruction, children learn to pull a zipper, twist a doorknob, and unstick the plastic on a piece of individually wrapped cheese. Moreover, knowing the designed action is not sufficient for implementation (Rachwani et al., 2019). Using designed affordances depends on the fit between body characteristics and the features of the artifact - the notion behind child-resistant packaging.

Independent of the designers' intentions, the world of objects, surfaces, and places offers unlimited possibilities for action. Eleanor Gibson (1992) said that watching children on a playground is a revelation of attention to affordances. Children swoosh down, climb up, and hide under the chute of the slide. They swing on the monkey bars, hang by their knees, and balance upright on the rungs. Any small object presents a compelling opportunity for infant exploration with hands, eyes, and mouth. Infants carry objects to share with their caregivers, to place in different locations, and for no discernible reason except their apparent delight in carrying things that afford carrying (E.J. Gibson, 1988; Heiman, Cole, Lee, \& Adolph, 2019). Even in a seemingly empty room, infants find things to do. They poke their fingers into indents in the floor, pick up tiny crumbs from the carpet, and use any small protuberance to try to climb the walls (Fig. 1 in Hoch, O’Grady, \& Adolph, 2019).

\section{Perceiving Affordances}

The richness of infants' behavior provides many ways to study learning in the context of development. But only by experimentally varying affordances for action can researchers assess the extent to which infants flexibly tailor their behavior to changes in local conditions. The general strategy is to identify an appropriate task, measure the affordance relations, determine whether infants perceive the affordances accurately, characterize the information-gathering behaviors that support infants' perception, and finally relate all of this to developmental changes in the infant-environment system.

Luckily, infants are highly motivated to do a variety of locomotor, manual, and postural tasks, and they will happily persist over dozens of trials. Over the years, I've tested affordances for infants (crawling, walking, sitting, reaching, etc.) with an array of adjustable apparatuses (slopes, drop-offs, bridges, gaps, apertures, ledges, overhead barriers, underfoot barriers, spinning chairs, objects varying in dimensions and locations, etc.), and other researchers have done likewise (for reviews, see Adolph \& Berger, 2006; Adolph, 2008; Adolph \& Robinson, 2013, 2015; Adolph \& Hoch, 2019; Rachwani et al., in press).

Bodies and skills differ widely among infants of the same age, so possibilities for action also differ. Thus, to measure affordances, for say, walking down slopes, possibilities for action must be determined for each infant individually. With a continuously adjustable apparatus, the degree of slant (or any environmental unit) can be related systematically to each infant's performance. When the slant is set to $0^{\circ}$, all infants can walk, and when it is set between $50^{\circ}$ and $90^{\circ}$, none can manage it. Between these end points, affordances for walking are probabilistic and depend on each in- 
fant's abilities. Psychophysical methods yield an S-shaped affordance function based on the infant's success rate at each unit, and the possibilities for action can be characterized by an affordance "threshold" at some criterion point along the function (e.g., Adolph, 1995, 1997; Adolph \& Berger, 2006; Franchak \& Adolph, 2014). The affordance threshold changes as infants' bodies grow and locomotor skill increases (e.g., threshold values increase as infants are able to walk down steeper slopes and higher drop-offs, and threshold values decrease as infants are able to walk along narrower bridges and ledges).

Because infants are preverbal, researchers cannot ask them whether a slope (drop-off, bridge, etc.) is possible or impossible for walking. Instead, infants' perception of affordances is based on their behavior (e.g., whether they attempt to walk). Infants are presented with test trials at various environmental units normalized to their individualized affordance thresholds. Infants can attempt the test increments or not. These data yield a decision function based on the infant's attempt rate at each unit. If infants scale their decisions to the actual affordances for action, the affordance and decision functions are parallel. If their decisions are perfectly accurate, the curves are superimposed. However, unlike the affordance function, which asymptotes near $100 \%$ and $0 \%$ success, the decision curve need not be well behaved: infants can fail to perceive affordances and attempt to walk down every slope or they can respond erratically. Note, the affordance function is based on successful and failed attempts, (successes)/(successes + failures), and the decision curve is based on attempts, regardless of whether they were successful, (successes + failures)/(successes + failures + refusals).

Infants' behaviors leading up to and following each decision yield insights into how they gather and use perceptual information about the affordance (for reviews, see Adolph, 2008; Adolph \& Berger, 2006; Adolph \& Hoch, 2019; Adolph \& Robinson, 2013, 2015; Rachwani et al., in press). In locomotor tasks, infants spontaneously explore affordances by slowing down as they approach the obstacle, looking and touching the obstacle, and testing alternative methods of locomotion. They peer over the edge of a precipice, poke a hand or foot out to feel the surface, and rock at the brink to generate torque around their wrists or ankles; they insert their hands, legs, or heads into an aperture or under a barrier. They squat, sit down, pivot in circles, and lie down in prone or backing positions to test alternative methods of locomotion. They modify their gait to navigate the obstacle (e.g., take tiny, slow steps to brake forward momentum on downhill slopes) or discover and use a variety of alternative means to solve the locomotor problem (slide down slopes on their bottoms, backward feet first, or on their bellies head first). Infants also request social information and assistance using vocalizations and gestures to appeal to their caregivers and experimenters for help.

\section{Behavioral Flexibility and Learning to Learn}

Dozens of experiments with various apparatuses indicate that infants do not perceive affordances when they first acquire a new skill in development; behavioral flexibility emerges gradually over several months of everyday experience (for reviews, see Adolph \& Berger, 2006; Adolph, 2008; Adolph \& Robinson, 2013, 2015; Adolph \& Hoch, 2019; Rachwani et al., in press). For example, in their first weeks of crawling 
and walking, infants tumble repeatedly over the brink of impossibly steep slopes, requiring rescue by an experimenter. Over weeks of crawling and walking, infants' perception becomes increasingly accurate. After several months of crawling and walking experience, infants discern safe from risky slopes within $2^{\circ}$ of accuracy. Exploratory activity, gait modifications, and appeals for social assistance generally track infants' decision functions.

Learning is robust across changes in infants' bodies and skill levels (i.e., changes in the affordance threshold). Experienced crawlers and walkers update their decisions from session to session as their bodies grow and locomotor skill improves. They even accurately update their decisions from trial to trial in accordance with experimental manipulation of their bodies and skills. At the same degree of slope, for example, they attempt to walk while wearing feather-weight shoulder-packs or rubber-soled shoes but refuse to walk while wearing lead-weight shoulder-packs or Teflon-soled shoes (for reviews, see Adolph \& Robinson, 2013, 2015; Adolph, Kretch, \& LoBue, 2014; Adolph \& Hoch, 2019).

Learning, however, does not transfer from earlier to later developing skills. Experienced crawlers who precisely perceive affordances for crawling attempt to walk down impossibly steep slopes and high drop-offs when they face the same obstacles as new walkers (Adolph, 1997; Adolph, Tamis-LeMonda, Ishak, Karasik, \& Lobo, 2008b; Kretch \& Adolph, 2013; Karasik, Tamis-LeMonda, \& Adolph, 2016; but see Witherington, Campos, Anderson, Lejeune, \& Seah, 2005). Infants who detect affordances for spanning gaps in an experienced sitting posture plunge headfirst into impossibly wide gaps when tested moments later in a novice crawling posture (Adolph, 2000). Experienced cruisers who accurately gauge affordances for cruising across gaps in a handrail attempt to cruise into impossibly wide gaps in the floor (Adolph, Berger, \& Leo, 2011). And learning is no faster for the next skill in development. Infants show separate, parallel learning curves for sitting, crawling, cruising, and walking.

What do infants learn that promotes such impressive flexibility within a developing skill and such rigid specificity across different skills in development? The data argue against several commonsense explanations. Improvements do not depend on experience with particular obstacles because experienced crawlers and walkers with no prior exposure to steep slopes, high drop-offs, narrow bridges, and so on behave the same as infants who are tested longitudinally (Adolph, 1997; Gill, Adolph, \& Vereijken, 2009). Infants do not learn static facts about their bodies or skills ("My legs are short," "I'm a skilled walker") because experienced infants update their assessments to take their changing bodies and skills into account. Infants do not learn fixed associations between environmental stimuli and outcomes ("Steep slopes are dangerous") because they attempt seriously impossible obstacles in a novice posture but not an experienced one. They do not acquire fear of heights because experienced crawlers and walkers treat narrow bridges the same, regardless of whether the bridge spans a small or large drop-off (see Adolph et al., 2014). They do not learn to mind their mothers (urging them, “Walk!” or "Don't walk!”) because experienced infants ignore unsolicited social information from caregivers except in the regions of actual uncertainty around their affordance threshold (e.g., Adolph et al., 2008b; Tamis-LeMonda et al., 2008; Karasik et al., 2016). And they do not learn that an experimenter will rescue them if they fall because the same infants who were caught dozens of times in their inexperienced posture avoid the obstacle when tested in their experienced posture 
(Adolph, 1997, 2000). Infants do not even learn particular solutions for coping with particular locomotor problems ("Back down steep slopes") because they use varied alternative locomotor methods from trial to trial (e.g., Adolph, 1997; Kretch \& Adolph, 2013).

Instead of learning fixed facts, stimulus-response associations, social contingencies, or particular solutions, infants acquire behavioral flexibility (Adolph \& Berger, 2006; Adolph, 2008; Adolph \& Robinson, 2013, 2015; Adolph \& Hoch, 2019; Rachwani et al., in press). They learn to generate and detect information for affordances at each moment - what they can do right now with this body and these skills in this environment for this task. Borrowing Harlow's (1949) phrase, they are "learning to learn." Indeed, prescribed behaviors and permanent solutions would be maladaptive in an ecosystem that is continually changing. A mental library of fixed solutions is not viable in the long term because yesterday's solution may no longer work with today's body, skills, and environment. Learning in the midst of development results in learning that is sufficiently flexible to scale up to the novelty and variability that characterize everyday activity in the natural environment. The flux of a changing body in a variable world ensures that infants learn to perceive affordance relations (my current leg length and level of balance control relative to the features of this particular dropoff) rather than static facts (big drop-offs are dangerous, or my balance is shaky).

Why doesn't learning to perceive affordance relations transfer from old to new skills in development? Why should it? Affordance relations for crawling and walking, for example, are completely different. Exploratory movements to generate information for affordances are different. And the information used to guide action is different. Thus, experience with each new skill in development teaches infants to perceive novel affordances for that skill. In Harlow's (1949) terms, learning to learn is limited by the boundaries of the problem space. Development creates a different problem space for each new motor skill.

\section{A Process Approach}

Years ago, Esther Thelen gave a talk in my department. One of the faculty in the audience asked why she used only gerunds and present participles to speak of psychological functions - "perceiving" rather than perception, "remembering" rather than memory, "thinking" rather than cognition. "Exactly!" Esther said, "because psychological functions are dynamic processes, not static mental structures." In her view, mental activities, behaviors, and abilities exist only in the here and now, emerging as needed in the present moment (Witherington, 2007, 2015). She used gerunds to avoid reifying dynamic processes.

Eleanor Gibson (2003) said in her "ruminations of an opinionated aged psychologist" that reductionism and its modern vestiges are a wrong turn in psychology. Psychology need not be motivated by science-envy for the reductionist, clockwork world of traditional physics (that ironically was replaced by the entangled, interactive world of modern physics). She rejected mechanistic explanations that presume a lock-step notion of causality, as if the behavior of animals can be explained by the same processes that govern the behavior of machines (E.J. Gibson, 1994).

I agree that a focus on fixed mental structures and architectures draws attention away from processes of change and that a mechanistic, "animal-as-machine" view 
does not capture the dynamic, probabilistic nature of animals' behavior. But I am not adverse to nouns, and like Witherington (2019), I find it useful to think of animals' abilities as potentials for action that exist across time and place. My ecological approach is a process approach because the goal is to characterize and explain the processes that underlie learning in development. Of course, many researchers in cognitive and language development also focus on change processes (for reviews, see Granott \& Parziale, 2002; Siegler, 2006). However, the beauty of studying behavior instead of mental functions is that the changes are directly open to observation (Adolph \& Berger, 2006; Adolph \& Robinson, 2013, 2015; Adolph et al., 2018).

\section{Change over Time}

Change only occurs over time. Thus, a process approach takes time seriously (Adolph, Robinson, Young, \& Gill-Alvarez, 2008a; Adolph \& Robinson, 2011, 2013, 2015). Time can be carved into ever-smaller and ever-larger intervals, and briefer time periods are nested inside of lengthier ones. Millisecond changes in the trajectory of an infant's look or walking step are nested within a series of eye and leg movements that occur within a second or across several seconds. One behavioral time series follows another so that tens of thousands of looks and thousands of steps accumulate over the waking day. These changes, in turn, are nested within improvements in looking and walking movements that play out over longer time scales of days, weeks, months, and years. Evolutionary time is likely the largest meaningful time unit, but for developmental psychologists, the important changes occur within the life span of the individual.

Changes typically occur asynchronously for different behaviors, so behavioral time series are overlapping and interleaved. Looking and walking overlap in real time; one behavior precedes and then follows the other, with recurrent starts and stops in each behavior. Changes in looking and walking movements are also asynchronous at larger time scales, with alternations between faster and slower periods of improvement in each behavior. Moreover, improvements in one behavior facilitate changes in the other at multiple time scales (seeing something gives infants an immediate destination to go to; the ability to walk expands infants' visual world and gives them more things to see).

Real infant behavior occurs in real time in real infants. Developmental stages and the "average" infant are only useful abstractions (and sometimes do not reflect any actual set of behaviors or any actual infant at all!). Thus, to study learning in development, behavior must be sampled at different time units, starting with real time (i.e., the smallest time period that captures the behavioral event), and then summarized over each increasingly larger time unit for each infant. Potentially useful summaries include all the usual statistics: binary data, rates, frequencies, accumulated totals, measures of central tendency, measures of variability, temporal contingencies, and functions that capture change over time.

For example, in experiments testing infants' perception of affordances for walking down slopes, the behaviors of interest can be microcoded from video at 30 frames per second. Within each trial, the temporal contingencies between exploratory behaviors (e.g., looking, touching), social expressions (vocalizations, facial and manual gestures), displacement behaviors (turning away, pulling at diaper, etc.), and deci- 
sions can be analyzed. Each trial can then be summarized in various ways - as binary data points (e.g., attempt or refuse to walk), time series of contingencies, or as continuous quantities (latency to descend, accumulated durations of looking and touching, frequency of positive and negative vocalizations, frequency of shifts in position, change in step length while approaching the brink, and so on). Then each infant's trials can be summarized over the course of the session as a set of curves to represent change in the infant's decisions, exploratory behaviors, social expressions, gait modifications, and so on in relation to the affordances at each degree of slant. Each infant can be tested longitudinally at different points in development (e.g., from the first to nth week of walking) and the data again summarized as a curve, with weeks on the $x$ axis, and perhaps an average across "risky" slopes on the $y$ axis. Alternatively, different infants can be tested at different points in development (novice and experienced walkers, experienced crawlers and novice walkers, shorter and taller infants, etc.), or developmental changes can be accelerated with training studies or simulated with various experimental manipulations.

Comparing each infant's data at each time unit (e.g., at the trial, session, and developmental levels) reveals the extent to which the behaviors generalize across infants. Do all, most, or only some infants ramp up their exploratory behavior within trials? Respond adaptively to impossibly steep slopes? Find alternative methods of locomotion for descent? Fail to transfer their behaviors from crawling to walking? In fact, nearly all infants show all of these behavioral phenomena, but to different degrees, and only when they have several months of locomotor experience (Adolph, 1995, 1997; Adolph et al., 2008b; Tamis-LeMonda et al., 2008; Gill et al., 2009).

The hardest problem in dealing with time is determining the appropriate sampling intervals. Behavior must be sampled at time units that capture the behavioral event. If the sampling resolution is too low, the event is lost (like watching a choppy video), and worse, sometimes researchers do not even know what behavioral events are relevant. For example, an infant's reach is so fast that video at $30 \mathrm{~Hz}$ captures only the beginning, as the arm moves forward, and the end, when the hand contacts the object; the middle period is mostly a blur. Higher sampling resolution $(>100 \mathrm{~Hz})$ with high-speed motion trackers shows that infants' first reaches are composed of multiple behavioral events as their hand jerks its way toward the target (for reviews, see Adolph \& Berger, 2006; Corbetta, 2009; Adolph \& Robinson, 2015). These shorter events are meaningful because they indicate that reaching involves corrections in the hand trajectory toward the target or fluctuations in the control of the arm.

Developmental changes in infants' bodies and skills must be sampled daily (Adolph et al., 2008a; Adolph \& Robinson, 2011, 2013, 2015). Infants' body growth, for example, does not follow the continuous trajectory pictured on standard growth charts (Kuczmarski et al., 2002), at least not in any real baby. The misrepresentation results from fitting idealized curves through data obtained at overly large sampling intervals (quarterly or yearly). Daily measurements reveal that growth is actually episodic, with dramatic spurts - up to $2 \mathrm{~cm}$ in height - occurring in a single day, separated by plateaus of days or weeks when little or no growth occurs (Lampl, 1993; Lampl \& Thompson, 2007; Caino, Kelmansky, Adamo, \& Lejarraga, 2010). The consequence of episodic growth for learning in development is that infants can wake up in a different body than the one they had when they went to sleep.

Similarly, infant motor skill acquisition does not follow the stage-like developmental trajectory pictured on standard milestone charts: before the onset day, in- 
fants cannot walk; after that day, they can. The misrepresentation results from overly large sampling intervals and from considering the first day of appearance as the onset (Wijnhoven et al., 2004). Daily sampling reveals that skill acquisition is actually variable. Motor skills sputter in and out of infants' repertoires. Infants can walk on one day, but not again until a few days later; they can sit on one day, but not on the next. Onset ages are arbitrary because infants can exhibit dozens of vacillations between being able and unable to perform the behavior (Adolph et al., 2008a; Adolph \& Robinson, 2011, 2015). It can take weeks or months before infants' basic motor skills stabilize. A consequence of variable skill trajectories is that learning via an emerging skill is an on-again-off-again process; it is limited to the moments and conditions when the skill can be expressed, and opportunities for learning compete with more stable solutions.

Moreover, daily sampling is necessary to identify the true trajectory of skill acquisition. Simulation of increasingly larger sampling intervals follows an inverse power function (Adolph et al., 2008a). With each additional day between observations, sensitivity to the true underlying trajectory drops precipitously. Whereas only $16 \%$ of 261 data sets had stage-like trajectories when sampled daily, 93\% showed a single stage-like trajectory when sampled monthly - a sampling rate that is normally considered heroic for a longitudinal study of infant development.

Microcoding! $100 \mathrm{~Hz}$ ! Daily sampling! Of course, frequent sampling incurs cost, and oversampling is possible. However, the costs of oversampling are all practical and logistical, not interpretational. Moreover, any time series can be down-sampled or smoothed to a lower grain of resolution. In fact, researchers routinely oversample physiological and movement data and then use smoothing functions to reduce noise and detect underlying patterns. In other words, researchers can recover the pattern of change from oversampled data, but the converse is not true: researchers cannot recover the patterns of change from data sampled at overly large time intervals (Adolph et al., 2008a; Adolph \& Robinson, 2011).

\section{Age, Experience, and Opportunities for Learning}

Characterizing change over time is critical, but it is only the first step. Explaining change over time is the next step, and it is equally critical. The need for explanation does not imply a need for reductionism (e.g., physiological or neural correlates of behavior) or a need for explanation at the macrolevel (e.g., cultural context or political climate), and neither level is privileged. Meaningful explanations of behavior can reside at their own level of function (E.J. Gibson, 1994).

More specifically, understanding learning in development requires explanations at each successive time unit - the stream of behavior in real time, the changes in behavior across trials in a session or successive encounters within a day, and the changes in behavior across longer time spans that reflect important developments in the ecosystem (infants' developing bodies, brains, skills, and environments). At shorter time units, the process of learning to learn is easily open to inspection, but at longer time intervals, it is not. Given the practical difficulties of collecting daily samples of developmental change, research on infants' perception of affordances has made substantial progress toward explanation at the time intervals within a day. Less so at longer time intervals. 
In real time (i.e., with seconds on the $x$ axis), learning to learn involves a graduated series of information-gathering behaviors, where information generated moments earlier instigates the exploration that follows. All forms of information seeking sequentially ramp up, from less to more costly activities as more information is needed to make a decision (for reviews, see Adolph et al., 2018; Adolph \& Hoch, 2019). In locomotion, peripheral vision is essentially free because the eyes are parked in front of the body. Other forms of information seeking are more costly because they entail more time and effort. Peripheral depth cues from a distance instigate a turn of the head and eyes toward the obstacle. If the brief glance indicates the obstacle is negligible, infants do not hesitate. But if the path looks risky, infants collect additional information. They may vocalize and gesture toward their caregiver or turn to the experimenter for help. Receiving no social assistance, they figure it out for themselves. They slow down, shorten their steps, and stop to gather haptic information by touching the obstacle. If haptic exploration indicates that the obstacle is passable, then infants go, but if touching suggests otherwise, they test alternative routes and methods of locomotion. If their tests lead to the discovery of a new strategy, they use it; otherwise, they stay put.

Experienced infants can safely skip steps in the sequence (e.g., the sight of a large drop-off at a distance can instigate an immediate postural shift to scoot down), but if earlier behaviors fail to generate the necessary perceptual information, then infants cannot perceive affordances accurately. For instance, visual information does not reliably specify slippery or squishy surfaces. Infants step right onto a shiny, slippery patch of ground or into a bumpy foam pit, and fall. Older children and adults do likewise (for reviews, see Adolph \& Joh, 2009; Adolph \& Hoch, 2019).

With trials, minutes, or hours on the $x$ axis, little changes. Infants show little evidence of acquiring behavioral flexibility across consecutive trials or across dozens of trials in a session. Novice infants' falls on earlier trials do not prompt more adaptive responses on later trials, and experienced infants show consistently adaptive responses from their first to last trial (e.g., Adolph, 1995, 1997). Whereas adults can quickly learn to associate the look of a slippery or squishy surface with the consequences of falling, infants and preschoolers fall repeatedly on consecutive trials (Adolph \& Joh, 2009). They show no evidence of one-trial learning, but why should they? In everyday life, the average toddler falls 17 times per hour, regardless of the color or visible texture of the ground surface (Adolph et al., 2012). They ignore the surface appearance of the ground because it is not typically relevant for balance and locomotion (Adolph \& Joh, 2009).

When sessions are nested within larger time units (i.e., days, weeks, or months on the $x$ axis), learning to learn shows gradual improvements. The acquisition of behavioral flexibility in human infants and monkeys is extremely slow (Harlow, 1949; Adolph, 1997). What is the explanation for this protracted learning? What is the underlying process? Experience predicts behavioral flexibility independently of infants' age (e.g., Adolph, 1997; Kretch \& Adolph, 2013). But regardless of their predictive power, neither age nor experience can explain improvements in behavioral flexibility. Elapsed time is not an explanatory variable (Adolph \& Berger, 2006; Adolph \& Robinson, 2013, 2015; Adolph et al., 2018). In Wohlwill's (1970) harsh assessment, time itself is conceptually empty, and too often serves as a "cloak for ignorance" (p. 50).

Age is the most popular independent variable in developmental psychology, but age is not an independent variable at all. Children are not randomly assigned to age groups and each child is or will be a member of every age group. Likewise, children's 
age is a wonderful predictor of behavior, but treating age group as an independent variable in an analysis of variance or as a predictor in a regression analysis imbues age with a causal power it does not have (Wohlwill, 1970, 1973). Age is merely a crude stand-in for unspecified factors that underlie the developmental changes. It confuses the passage of time with the factors responsible for enabling developmental change. Similarly, despite the arbitrary nature of skill onset dates, researchers (including me) routinely put experience on the $x$ axis, where "experience" represents the number of days since skill onset. This is tantamount to considering test age (number of days since birth) as "life experience." Like chronological age, motor experience - that is, "crawling age" or "walking age" - is a powerful predictor of changes in motor skill. But just like chronological age, experience measured as elapsed time is merely a convenient proxy for the unspecified types of practice or exposure that underlie the developmental changes.

A satisfying explanation at the developmental level would replace time on the $x$ axis with the actual factors responsible for change. Descriptions of infants' everyday activity provide several reasonable possibilities. Infants' everyday locomotor experience consists of immense amounts of time-distributed, variable, error-ridden practice. During each hour of free activity with a caregiver, walking infants average 2,400 steps, travel the distance of 8 football fields, and fall 17 times (Adolph et al., 2012). When infants play without their caregivers, the numbers nearly double (Hoch et al., 2019). Infants' natural walking paths meander wildly and are punctuated by frequent starts and stops; they take steps in every direction and travel over most of the surfaces (carpet, linoleum, etc.) and elevations (stairs, slopes, etc.) in the available space (Lee et al., 2018); and infants initiate most bouts of locomotion with no apparent motivation except the urge to move (e.g., Hoch et al., 2019).

Which aspects of infants' natural practice regimen facilitate learning to learn? Feedback from errors does not facilitate (or impede) learning to learn. In fact, infants and caregivers largely ignore infants' plentiful everyday falls (Han, Borenstein, Hasan, Tamis-LeMonda, \& Adolph, 2019). Navigating to goals is relatively infrequent and likely not necessary. And I suspect that the sheer quantity of practice does not underlie learning to learn. That is, if infants took the same number of time-distributed steps on a motorized treadmill as they do in everyday life, I doubt they would learn to perceive affordances for balance and locomotion. Rather, I hypothesize that the accumulated variety of locomotor and postural experiences with different body-environment relations leads to the acquisition of behavioral flexibility. The strongest test of this hypothesis would require a daily record of each locomotor and postural event, including what infants are wearing and carrying and the immediate environmental context, combined with longitudinal tests of the infants' perception of affordances. It's daunting. However, simulations with robots trained on infants' natural walking paths support the idea that a variety of experiences facilitates flexible, functional performance (Ossmy et al., 2018). Training studies in which infants receive enhanced practice with varied body-environment relations are under way.

\section{Enabling Change through a Cascade of Behavioral and Developmental Events}

Causality is a tricky concept in behavioral and developmental science. If causality refers to some mechanism that leads inevitably to a given behavioral or developmental outcome, then it is unlikely to be a useful concept. Behavioral and develop- 
mental pathways are too convoluted, redundant, context specific, and plastic for that. Often, multiple factors cooperate to secure a particular outcome: leg strength, balance control, social pressures, caregiving practices, and motivation must coalesce for the emergence of walking (for reviews, see Adolph \& Robinson, 2013, 2015; Adolph et al., 2010; Adolph, 2018; Adolph et al., 2018; Adolph \& Hoch, 2019). Without all of these factors (and perhaps more), healthy infants cannot walk, and they may continue to crawl into adulthood (a family of adult crawlers in a remote region of Turkey did not walk until researchers provided social pressure and motivation to do so!). Different pathways can lead to the same end point: some infants take their first walking steps by falling forward and catching themselves with their moving leg; some twist their legs and torso to generate the steps; and others keep stiffly upright and barely lift each foot. Although their developmental pathways differ, infants eventually converge to a similar walking pattern. Different outcomes can result from the same starting point: All healthy infants alternate their legs at birth, but differences in caregiving practices can lead to first steps at 8 months or at 14 months or at $>20$ months. In cultures where caregivers exercise infants' upright steps, they walk sooner; in cultures where caregivers constrain infants' movements, they walk later; and in cultures where caregivers do neither, infants walk somewhere in between.

Instead of a linear causal chain, I prefer the idea that earlier behavioral or developmental events "enable" rather than cause the later ones (Adolph \& Robinson, 2013, 2015; Adolph et al., 2018; Adolph \& Hoch, 2019). Earlier events can lay the foundation for later events; they can channel later events and make them more likely (Campos et al., 2000). My notion of "enabling" lies somewhere between Gottlieb's (1991) notions of "induction" (prior event $\mathrm{X}$ is necessary for later target event $\mathrm{Y}$ ) and "facilitation" (prior event $\mathrm{X}$ alters the developmental timing of later event $\mathrm{Y}$ ). In my view, a prior enabling event $\mathrm{X}$ can do more than change the timing of a later event $\mathrm{Y}$, but $\mathrm{X}$ does not guarantee the later event $\mathrm{Y}$, and other events $\mathrm{A}-\mathrm{Z}$ can also lead to $\mathrm{Y}$.

In real time, for instance, the sight of an obstacle in the path typically instigates gait modifications and exploratory actions. But it does not force infants to modify their gait, and it does not oblige them to touch the surface or to adopt an alternative method of locomotion. Moreover, access to visual information does not guarantee that infants will respond adaptively. Indeed, novice crawlers and walkers see the same steep slopes and large drop-off that experienced infants see, but the novice infants do not respond adaptively. Seeing the obstacle just makes the next steps in the behavioral cascade more likely. Over longer time scales, new (and improved) motor skills - visual, postural, manual, and locomotor - create new opportunities for learning and can thereby instigate cascading waves of change. As in real time, there is no guarantee that infants capitalize on the available opportunities, or that learning occurs. Nevertheless, the opportunities are available and can spur developments far afield from the original accomplishment (Adolph \& Robinson, 2013, 2015; Adolph et al., 2018; Adolph \& Hoch, 2019).

Postural development, for example, is a great enabler. It provides the foundation upon which other actions are built. Head control sets the stage for effective visual exploration of the environment, trunk control provides a stable base for manual actions, and upright posture allows for mature forms of locomotion. Thus, improvements in postural control can create developmental cascades into seemingly far-flung domains of function (for reviews of postural cascades, see Adolph \& Robinson, 2015; Adolph, 2018; Adolph \& Hoch, 2019; Rachwani et al., in press). Acquisition of a stable sitting 
posture, for example, lays the groundwork for three-dimensional form perception because sitting facilitates prehension and multimodal object exploration, which, in turn, facilitate the acquisition of knowledge about the three-dimensionality of objects. Postural training from 2-3 months of age leads to accelerated postural, manual, and locomotor skills over the next 12 months and facilitates infants' understanding of means-ends relations.

Similarly, the advent of walking is an important enabling event (for reviews of locomotor cascades, see Adolph \& Robinson, 2013, 2015; Adolph \& Tamis-LeMonda, 2014; Adolph, 2018; Adolph et al., 2018; Adolph \& Hoch, 2019). Compared with crawling, walking allows infants to move faster, spend more time in motion, take more steps per hour, travel longer distances, cover more area, visit more places, and spend more time away from their caregivers. While crawling, infants' view is largely limited to the ground in front of their hands, but in an upright posture, the whole room and its contents swoop into view. Walkers' expanded view of the environment provides them with increased visual access to people, places, and things. It makes it easier for infants to locate distant objects, and they spend more time accessing and engaging with objects that were previously out of reach. Although crawlers can carry objects, walking frees up infants' hands for carrying and exploring objects, and they do so more frequently. Carrying objects, in turn, allows infants to capitalize on new ways of sharing objects with others. Instead of holding up objects from a stationary position to bid for caregivers' attention, walking infants pick up the object, and carry it to the caregiver. These moving bids elicit new forms of verbal input from caregivers, who respond with language about what infants can do with the object in hand. Walking also leads to an increase in infant-initiated joint engagement and attention to caregivers' joint engagement cues (e.g., following gaze and points), and it spurs infants to direct more pointing and waving gestures to their caregivers. Finally, each day of walking results in increases in infants' receptive and productive vocabulary, independently of infants' age. In short, the development of walking allows infants to go more, see more, do more, play more, hear more, learn more, and talk more.

\section{Conclusions: Learning in Development}

Learning and development are unwieldy, slippery concepts, at times mind-blowingly wonderful, at times mind-numbingly exhausting, but always just beyond grasp. Metaphors (like Waddington's famous landscape), mathematical models (as in dynamic systems and machine-learning algorithms), and formal simulations (with computer programs and robots) only get partway there. Understanding change in a complex biological system like a human infant is not easy or straightforward. Part of the difficulty stems from the challenge of characterizing change processes that occur over multiple, nested, interleaved, and interacting time scales. Moreover, researchers must study the development of something in some animal learning something. Thus, part of the difficulty arises from the tension between staying true to the details of the phenomenon undergoing change and the challenge of abstracting change processes beyond the phenomena of study. The best and the bravest give it a go. I have opted for a middle road. To make the problem more manageable, my approach is to study learning in - not and - development, and to limit the content of learning to behavioral flexibility. 


\section{Keeping the Wonderful Manageable}

My ecological approach is a functional, process-oriented approach to behavioral change. Behavior only occurs in real time, but the processes that constrain and promote behavior occur at multiple time scales. At every time scale, the focus is on the processes that make behaviors flexibly attuned to local conditions, that is, on perceiving and exploiting affordances for action. Human infants are not ready made to perceive affordances. They have to learn how to do it, and the learning takes place in a system that is undergoing continuous change - their bodies, brains, skills, and environments are in continual flux. Likely, learning to perceive affordances at the same time that affordances are changing ensures that infants learn how to learn. And learn they do. Their behavioral experiences are immense, varied, and rich. As a consequence, by the time infants are about 18 months of age, they perceive possibilities for basic postural, locomotor, and manual actions with impressive accuracy, and they begin learning about the designed actions of everyday artifacts. Development likely constrains the problem space to make learning more tractable. The world is generally not more blooming and buzzing than infants can manage (with the help of their caregivers).

My ecological approach, like that of the Gibsons, is limited in scope. But my hope is that it is broad enough to both explain and celebrate those aspects of behavior that allow animals to adapt to their environments and to exert change on their environments - to do what they need and want to do. I also hope that a focus on observable, functional motor behaviors yields a data set of wondrous phenomena that can serve as a model system for understanding change processes more generally.

\section{Epilogue}

Eleanor Gibson published her first paper on perceptual learning in 1932 with her soon-to-be husband (J.J. Gibson, Jack, \& Raffel, 1932), and her last book in 2002, a biography of their entwined intellectual lives (E.J. Gibson, 2002). Between these time points, she saw the rise and fall of behaviorism, the cognitive, computational, and neuroscience revolutions, the rebirth of nativism in developmental psychology, and the waxing and waning of various systems approaches to development, including the frameworks proposed by Piaget, Werner, Bronfenbrenner, Gottlieb, and Thelen. But through it all, she kept her focus on behavior from a functional approach in an ecological systems framework. I am old enough now to have lived through the widespread adoption of neuroscience and computational approaches in developmental psychology (e.g., Munakata, 2006; Stiles, Brown, Haist, \& Jernigan, 2015), a generation of debates about nativist approaches (e.g., Spencer et al., 2009), and more waxing and waning of systems approaches, including many variants of dynamic and developmental systems (e.g., Witherington, 2015). Through it all, I too have kept my focus on behavior from a functional and ecological approach, but one that also incorporates many ideas from dynamic and developmental systems views.

One of the most wonderful things about working with Eleanor Gibson at the end of her career (she was 77 when I became her doctoral student and 92 when she died) is that she had plenty of time to talk with her students about the wisdom she had accumulated over her 70 years of research. She was leery of psychological theories that 
were so broad as to be promiscuous or so narrow as to be superfluous. In her view, the right approach to psychology is one that asks the right questions. She advised us to focus our efforts on revising and refining our questions and concepts. She was never one to lavish praise on students. In fact, her highest praises to me were "fine" and "just fine," and I could never figure out which expression was better (Adolph \& Eppler, 2003). But I like to think that she would approve of my big question: How do infants learn - in the context of continual development - to flexibly tailor their behavior to the opportunities offered by the changing world around them?

\section{Acknowledgments}

This article is based on a presentation to the Jean Piaget Society in Amsterdam, May 31, 2018. Work on the article was supported by grants from the National Institute of Child Health and Human Development (R01-HD033486, R01-HD086034, and R01-HD094830) and the LEGO and Keen Foundations. I am grateful to David Witherington for insisting that I formalize my ecological approach and for inspiring us all to have big ideas. I thank Justine Hoch for her careful comments and clever suggestions about the manuscript. I thank David Witherington, Jan Boom, and Paul van Geert for the invitation to join them in thinking about the dynamics of development.

\section{References}

Adolph, K. E. (1995). Psychophysical assessment of toddlers' ability to cope with slopes. Journal of Experimental Psychology Human Perception and Performance, 21(4), 734-750. https://doi. org/10.1037/0096-1523.21.4.734

Adolph, K. E. (1997). Learning in the development of infant locomotion. Monographs of the Society for Research in Child Development, 62(3, Serial No. 251), 1-140. https://doi.org/10.2307/1166199

Adolph, K. E. (2000). Specificity of learning: Why infants fall over a veritable cliff. Psychological Science, 11(4), 290-295. https://doi.org/10.1111/1467-9280.00258

Adolph, K. E. (2008). Learning to move. Current Directions in Psychological Science, 17(3), 213-218. https://doi.org/10.1111/j.1467-8721.2008.00577.x

Adolph, K. E. (2018). Motor development. In M. H. Bornstein \& M. Arterberry (Eds.), The SAGE encyclopedia of lifespan human development (pp. 1450-1453). Thousand Oaks, CA: Sage.

Adolph, K. E. (2020). Ecological validity: Mistaking the lab for real life. In R. J. Sternberg (Ed.), My biggest research mistake: Adventures and misadventures in psychological research (pp. 187-190). New York, NY: Sage.

Adolph, K. E., \& Berger, S. E. (2006). Motor development. In D. Kuhn \& R. S. Siegler (Eds.), Handbook of child psychology: Vol. 2. Cognition, perception, and language (6th ed., pp. 161-213). New York, NY: Wiley. https://doi.org/10.1002/0470018860.s00584

Adolph, K. E., \& Eppler, M. A. (2003). Life after the lab (obituary for Eleanor Gibson). APS Observer, 16, 23.

Adolph, K. E., \& Hoch, J. E. (2019). Motor development: Embodied, embedded, enculturated, and enabling. Annual Review of Psychology, 70(1), 141-164. https://doi.org/10.1146/annurevpsych-010418-102836

Adolph, K. E., \& Joh, A. S. (2009). Multiple learning mechanisms in the development of action. In A. Woodward \& A. Needham (Eds.), Learning and the infant mind (pp. 172-207). New York, NY: Oxford University Press. https://doi.org/10.1093/acprof:oso/9780195301151.003.0007

Adolph, K. E., \& Kretch, K. S. (2012). Infants on the edge: Beyond the visual cliff. In A. Slater \& P. Quinn (Eds.), Developmental psychology: Revisiting the classic studies (pp. 36-55). London, UK: Sage Publications.

Adolph, K. E., \& Kretch, K. S. (2015). Gibson's theory of perceptual learning. In H. Keller (Ed.), International encyclopedia of the social and behavioral sciences (2nd ed., Vol. 10, pp. 127-134). New York, NY: Elsevier. https://doi.org/10.1016/B978-0-08-097086-8.23096-1 
Adolph, K. E., \& Robinson, S. R. (2011). Sampling development. Journal of Cognition and Development, 12(4), 411-423. https://doi.org/10.1080/15248372.2011.608190

Adolph, K. E., \& Robinson, S. R. (2013). The road to walking: What learning to walk tells us about development. In P. Zelazo (Ed.), Oxford handbook of developmental psychology (pp. 403-443). New York, NY: Oxford University Press. https://doi.org/10.1093/oxfordhb/9780199958450.013.0015

Adolph, K. E., \& Robinson, S. R. (2015). Motor development. In L. Liben \& U. Muller (Eds.), Handbook of child psychology and developmental science (7th ed., Vol. 2, pp. 113-157). New York, NY: Wiley. https://doi.org/10.1002/9781118963418.childpsy204

Adolph, K. E., \& Tamis-LeMonda, C. S. (2014). The costs and benefits of development: The transition from crawling to walking. Child Development Perspectives, 8(4), 187-192. https://doi.org/10.1111/ cdep. 12085

Adolph, K. E., Berger, S. E., \& Leo, A. J. (2011). Developmental continuity? Crawling, cruising, and walking. Developmental Science, 14(2), 306-318. https://doi.org/10.1111/j.1467-7687.2010.00981.x

Adolph, K. E., Cole, W. G., Komati, M., Garciaguirre, J. S., Badaly, D., Lingeman, J. M., . . Sotsky, R. B. (2012). How do you learn to walk? Thousands of steps and dozens of falls per day. Psychological Science, 23(11), 1387-1394. https://doi.org/10.1177/0956797612446346

Adolph, K. E., Cole, W. G., \& Vereijken, B. (2015). Intraindividual variability in the development of motor skills in childhood. In M. Diehl, K. Hooker, \& M. Sliwinski (Eds.), Handbook of intraindividual variability across the lifespan (pp. 59-83). New York, NY: Routledge.

Adolph, K. E., Hoch, J. E., \& Cole, W. G. (2018). Development (of walking): 15 suggestions. Trends in Cognitive Sciences, 22(8), 699-711. https://doi.org/10.1016/j.tics.2018.05.010

Adolph, K. E., Hoch, J. E., \& Ossmy, O. (2020). James Gibson's ecological approach to locomotion and manipulation: Development and changing affordances. In J. B. Wagman \& J. Blau (Eds.), Perception as information detection: Reflections on Gibson's ecological approach to visual perception (pp. 248266). New York, NY: Taylor \& Francis. https://doi.org/10.4324/9780429316128-14

Adolph, K. E., Karasik, L. B., \& Tamis-LeMonda, C. S. (2010). Motor skills. In M. H. Bornstein (Ed.), Handbook of cultural development science: Vol. 1. Domains of development across cultures (pp. 6188). New York, NY: Taylor and Francis.

Adolph, K. E., Kretch, K. S., \& LoBue, V. (2014). Fear of heights in infants? Current Directions in Psychological Science, 23(1), 60-66. https://doi.org/10.1177/0963721413498895

Adolph, K. E., Robinson, S. R., Young, J. W., \& Gill-Alvarez, F. (2008a). What is the shape of developmental change? Psychological Review, 115(3), 527-543. https://doi.org/10.1037/0033-295X.115.3.527

Adolph, K. E., Tamis-LeMonda, C. S., Ishak, S., Karasik, L. B., \& Lobo, S. A. (2008b). Locomotor experience and use of social information are posture specific. Developmental Psychology, 44(6), 1705-1714. https://doi.org/10.1037/a0013852

Bernstein, N. A. (1996). On dexterity and its development. In M. L. Latash \& M. T. Turvey (Eds.), Dexterity and its development (pp. 3-244). Mahwah, NJ: Erlbaum.

Bix, L., de la Fuente, J., Sunder, R. P., \& Lockhart, H. (2009). Packaging design and development. In K. L. Yam (Ed.), The Wiley encyclopedia of packaging technology (pp. 859-866). Hoboken, NJ: Wiley.

Caino, S., Kelmansky, D., Adamo, P., \& Lejarraga, H. (2010). Short-term growth in head circumference and its relationship with supine length in healthy infants. Annals of Human Biology, 37(1), 108-116. https://doi.org/10.3109/03014460903251753

Campos, J. J., Anderson, D. I., Barbu-Roth, M. A., Hubbard, E. M., Hertenstein, M. J., \& Witherington, D. C. (2000). Travel broadens the mind. Infancy, 1, 149-219. https://doi.org/10.1207/ S15327078IN0102_1

Corbetta, D. (2009). Brain, body, and mind: Lessons from infant motor development. In J. P. Spencer, M. S. C. Thomas, \& J. L. McClelland (Eds.), Toward a unified theory of development: Connectionism and dynamic systems theory reconsidered (pp. 51-66). London, UK: Oxford University Press. https://doi. org/10.1093/acprof:oso/9780195300598.003.0003

Franchak, J., \& Adolph, K. (2014). Affordances as probabilistic functions: Implications for development, perception, and decisions for action. Ecological Psychology, 26(1-2), 109-124. https://doi.org/10.1080 /10407413.2014.874923

Gaver, W. W. (1991). Technology affordances. In S. P. Robertson, G. Olson, \& J. Olson (Eds.), Proceedings of the CHI'91 SIGCHI Conference on Human Factors in Computing Systems (pp. 79-84). New York, NY: ACM Press. https://doi.org/10.1145/108844.108856

Gesell, A. (1933). Maturation and the patterning of behavior. In C. Murchison (Ed.), A handbook of child psychology (2nd ed., Vol. 1, pp. 209-235). Worcester, MA: Clark University Press. https://doi. org/10.1037/11552-004 
Gibson, E. J. (1982). The concept of affordances in development: The renascence of functionalism. In W. A. Collins (Ed.), The concept of development: The Minnesota Symposia on Child Psychology (Vol. 15, pp. 55-81). Mahwah, NJ: Lawrence Erlbaum Associates.

Gibson, E. J. (1988). Exploratory behavior in the development of perceiving, acting, and the acquiring of knowledge. Annual Review of Psychology, 39(1), 1-41. https://doi.org/10.1146/annurev. ps.39.020188.000245

Gibson, E. J. (1991). An odyssey in learning and perception. Cambridge, MA: MIT Press.

Gibson, E. J. (1992, April). Perceptual learning and development. Colloquium to the Indiana University Department of Psychology, Bloomington, IN.

Gibson, E. J. (1994). Has psychology a future? Psychological Science, 5(2), 69-76. https://doi. org/10.1111/j.1467-9280.1994.tb00633.x

Gibson, E. J. (1997). An ecological psychologist's prolegomena for perceptual development: A functional approach. In C. Dent-Read \& P. Zukow-Goldring (Eds.), Evolving explanations of development: Ecological approaches to organism-environment systems (pp. 23-45). Washington, DC: American Psychological Association. https://doi.org/10.1037/10265-001

Gibson, E. J. (2002). Perceiving the affordances: A portrait of two psychologists. Mahwah, NJ: Lawrence Erlbaum Associates.

Gibson, E. J. (2003). What psychology is about: Ruminations of an opinionated aged psychologist. Ecological Psychology, 15(4), 289-295. https://doi.org/10.1207/s15326969eco1504_4

Gibson, E. J., \& Pick, A. D. (2000). An ecological approach to perceptual learning and development. New York, NY: Oxford University Press.

Gibson, J. J. (1958). Visually controlled locomotion and visual orientation in animals. British Journal of Psychology, 49(3), 182-194. https://doi.org/10.1111/j.2044-8295.1958.tb00656.x

Gibson, J. J. (1966). The senses considered as perceptual systems. Boston, MA: Houghton-Mifflin.

Gibson, J. J. (1979). The ecological approach to visual perception. Boston, MA: Houghton Mifflin.

Gibson, J. J., Jack, E. G., \& Raffel, G. (1932). Bilateral transfer of the conditioned response in the human subject. Journal of Experimental Psychology, 15(4), 416-421. https://doi.org/10.1037/ h0071059

Gill, S. V., Adolph, K. E., \& Vereijken, B. (2009). Change in action: How infants learn to walk down slopes. Developmental Science, 12(6), 888-902. https://doi.org/10.1111/j.1467-7687.2009.00828.x

Gottlieb, G. (1991). Experiential canalization of behavioral development: Theory. Developmental Psychology, 27(1), 4-13. https://doi.org/10.1037/0012-1649.27.1.4

Granott, N., \& Parziale, J. (2002). Microdevelopment: A process-oriented perspective for studying development and learning. In N. Granott \& J. Parziale (Eds.), Microdevelopment: Transition processes in development and learning (pp. 1-28). Cambridge, UK: Cambridge University Press. https://oi. org/10.1017/CBO9780511489709.001

Han, D. Y., Borenstein, H., Hasan, S., Tamis-LeMonda, C. S., \& Adolph, K. E. (2019, March). Falling like a baby: High frequency, low severity, and little evidence of deterrence. Society for Research in Child Development, Baltimore, MD.

Harlow, H. F. (1949). The formation of learning sets. Psychological Review, 56(1), 51-65. https://doi. org/10.1037/h0062474

Heiman, C. M., Cole, W. G., Lee, D. K., \& Adolph, K. E. (2019). Object interaction and walking: Integration of old and new skills in infant development. Infancy, 24(4), 547-569. https://doi.org/10.1111/ infa. 12289

Hoch, J. E., O’Grady, S. M., \& Adolph, K. E. (2019). It's the journey, not the destination: Locomotor exploration in infants. Developmental Science, 22(2), e12740. https://doi.org/10.1111/desc.12740

Karasik, L. B., Tamis-LeMonda, C. S., \& Adolph, K. E. (2016). Decisions at the brink: Locomotor experience affects infants' use of social information on an adjustable drop-off. Frontiers in Psychology, 7, 797. https://doi.org/10.3389/fpsyg.2016.00797

Kretch, K. S., \& Adolph, K. E. (2013). Cliff or step? Posture-specific learning at the edge of a drop-off. Child Development, 84(1), 226-240. https://doi.org/10.1111/j.1467-8624.2012.01842.x

Kuczmarski, R. J., Ogden, C. L., Guo, S. S., Grummer-Strawn, L. M., Flegal, K. M., Mei, Z., \& Johnson, C. L. (2002). 2000 CDC growth charts for the United States: Methods and development. Hyattsville, MD. Retrieved from https://doi.org/10.1542/peds.109.1.45

Lampl, M. (1993). Evidence of saltatory growth in infancy. American Journal of Human Biology, 5(6), 641-652. https://doi.org/10.1002/ajhb.1310050607

Lampl, M., \& Thompson, A. L. (2007). Growth chart curves do not describe individual growth biology. American Journal of Human Biology, 19(5), 643-653. https://doi.org/10.1002/ajhb.20707 
Lee, D. K., Cole, W. G., Golenia, L., \& Adolph, K. E. (2018). The cost of simplifying complex developmental phenomena: A new perspective on learning to walk. Developmental Science, 21(4), e12615. https:// doi.org/10.1111/desc. 12615

Levitis, D. A., Lidicker, W. Z., Jr., \& Freund, G. (2009). Behavioural biologists don't agree on what constitutes behaviour. Animal Behaviour, 78(1), 103-110. https://doi.org/10.1016/j.anbehav.2009.03.018

McGraw, M. B. (1935). Growth: A study of Johnny and Jimmy. New York, NY: Appleton-Century Crofts.

Munakata, Y. (2006). Information processing approaches to development. In D. Kuhn \& R. S. Siegler (Eds.), Handbook of child psychology: Vol. 2. Cognition, perception, and language (6th ed., pp. 426463). New York, NY: Wiley.

Norman, D. A. (2013). The design of everyday things, revised and expanded. New York, NY: Basic Books.

Ossmy, O., Hoch, J. E., MacAlpine, P., Hasan, S., Stone, P., \& Adolph, K. E. (2018). Variety wins: Soccerplaying robots and infant walking. Frontiers in Neurorobotics, 12, 19. https://doi.org/10.3389/fnbot.2018.00019

Rachwani, J., Hoch, J. E., \& Adolph, K. E. (in press). Action in development: Variability, flexibility, and plasticity. In C. S. Tamis-LeMonda \& J. J. Lockman (Eds.), The Cambridge handbook of infant development. Cambridge, UK: Cambridge University Press.

Rachwani, J., Tamis-LeMonda, C. S., Lockman, J. J., Karasik, L. B., \& Adolph, K. E. (2019). Learning the designed actions of everyday objects. Journal of Experimental Psychology. General. Advance online publication. https://doi.org/10.1037/xge0000631

Siegler, R. S. (2006). Microgenetic analyses of learning. In D. Kuhn \& R. S. Siegler (Eds.), Handbook of child psychology: Vol. 2. Cognition, perception, and language (6th ed., pp. 464-510). New York, NY: Wiley. https://doi.org/10.1002/9780470147658.chpsy0211

Spencer, J. P., Blumberg, M. S., McMurray, B., Robinson, S. R., Samuelson, L. K., \& Tomblin, J. B. (2009). Short arms and talking eggs: Why we should no longer abide the nativist-empiricist debate. Child Development Perspectives, 3(2), 79-87. https://doi.org/10.1111/j.1750-8606.2009.00081.x

Stiles, J., Brown, T. T., Haist, F., \& Jernigan, T. L. (2015). Brain and cognitive development. In L. Liben \& U. Muller (Eds.), Handbook of child psychology and developmental science (7th ed., Vol. 2, pp. 9-62). New York, NY: Wiley. doi:https://doi.org/10.1002/9781118963418.childpsy202

Tamis-LeMonda, C. S., Adolph, K. E., Lobo, S. A., Karasik, L. B., Ishak, S., \& Dimitropoulou, K. A. (2008). When infants take mothers' advice: 18-month-olds integrate perceptual and social information to guide motor action. Developmental Psychology, 44(3), 734-746. https://doi.org/10.1037/00121649.44.3.734

Thelen, E. (1996). The improvising infant: Learning about learning to move. In M. R. Merrens \& G. G. Brannigan (Eds.), The developmental psychologists: Research adventures across the lifespan (pp. 2136). New York, NY: McGraw-Hill.

Thelen, E., \& Smith, L. B. (1994). A dynamic systems approach to the development of cognition and action. Cambridge, MA: MIT Press.

Thelen, E., \& Ulrich, B. D. (1991). Hidden skills: A dynamic systems analysis of treadmill stepping during the first year. Monographs of the Society for Research in Child Development, 56(1, Serial No. 223), 1-103. https://doi.org/10.2307/1166099

Wijnhoven, T. M. A., de Onis, M., Onyango, A. W., Wang, T., Bjoerneboe, G. E., Bhandari, N., . . al Rashidi, B. (2004). Assessment of gross motor development in the WHO Multicentre Growth Reference Study. Food and Nutrition Bulletin, 25(1, Suppl), S37-S45. https://doi. org/10.1177/15648265040251S106

Witherington, D. C. (2007). The dynamic systems approach as metatheory for devleopmental psychology. Human Development, 50(2-3), 127-153. https://doi.org/10.1159/000100943

Witherington, D. C. (2015). Dynamic systems in developmental science. In W. F. Overton \& P. C. M. Molenaar (Eds.), Handbook of child psychology and developmental science (7th ed., Vol. 1, pp. 63-112). New York, NY: Wiley. https://doi.org/10.1002/9781118963418.childpsy103

Witherington, D. C. (2019). Making sense of microdevelopment, macrodevelopment, and their interrelation: Commentary on van der Steen, Steenbeek, den Hartigh, and van Geert. Human Development, 63(1), 33-37. https://doi.org/10.1159/000501635

Witherington, D. C., Campos, J. J., Anderson, D. I., Lejeune, L., \& Seah, E. (2005). Avoidance of heights on the visual cliff in newly walking infants. Infancy, 7(3), 285-298. https://doi.org/10.1207/ s15327078in0703_4

Wohlwill, J. F. (1970). The age variable in psychological research. Psychological Review, 77(1), $49-64$. https://doi.org/10.1037/h0028600

Wohlwill, J. F. (1973). The study of behavioral development. New York, NY: Academic Press.

Ecological Approach

Human Development 2019;63:180-201 201 DOI: $10.1159 / 000503823$ 